\title{
Privatisasi Sempadan Pantai oleh Akomodasi Pariwisata di Denpasar
}

Alzaena Geanina Irnawana, 1, Ida Bagus Suryawana, 2

1 geaninairnawan@yahoo.co.id, 2 Idabagussuryawan@unud.ac.id

a Program Studi Sarjana Destinasi Pariwisata, Fakultas Pariwisata, Universitas Udayana, Jl. Dr. R. Goris, Denpasar, Bali 80232 Indonesia

\begin{abstract}
Abstact
The privatization of the current coastal border began to bloom in many areas of Bali. No exception in Sanur Beach, Denpasar. In this study the privatization of coastal border is done by the accommodation provider of Santrian Resorts and Villas, which houses two hotels, including Puri Santrian A Beach Resort and Spa and Griya Santrian A Beach Resort. The purpose of this research is to know the form of privatization conducted by Santrian Resorts and Villas at Sanur Beach. As well as knowing the Denpasar city government policy on the privatization of beach border in Sanur Beach. The research methodology used in this research is qualitative research. The method are use in-depth interview technique and observation. Santrian Resorts and Villas is right to practice the privatization of coastal border. Therefore, many activities of tourists, tourists and informal business actors in the field of tourism becomes disrupted. Although there is already a policy on coastal border made by the Denpasar City Government, the policy is considered not yet firm in following up the violation. This is one reason why the practice of beach border privatization is still rife.
\end{abstract}

\section{Keyword : Tourism Policy, Privatization of Coastal Border, Tourism Law}

\section{PENDAHULUAN}

Pariwisata saat ini menjadi salah satu ujung tombak Indonesia dalam menghasilkan pundipundi perekonomian. Hal ini dibuktikan dengan naiknya peringkat pariwisata pada urutan kedua penghasil devisa Negara (Udjianto, 2018). Oleh karena itu mulai banyak usahausaha dalam bidang pariwisata yang digencarkan di berbagai daerah di Indonesia. Menurut Undang-Undang Republik Indonesia Nomor 10 Tahun 2009 Tentang Kepariwisataan, Usaha Pariwisata adalah usaha yang menyediakan barang dan atau jasa bagi pemenuhan kebutuhan wisatawan dan penyelenggara pariwisata. Usaha pariwisata ini diharapkan dapat meningkatkan perekonomian dan juga meningkatkan kesejanteraan masyarakat.

Bali merupakan surga pariwisata di Indonesia, berbagai usaha pariwisata dapat dinikmati di pulau dewata ini. Penyedia akomodasi adalah salah satu usaha pariwisata yang merupakan aspek penting dalam kegiatan kepariwisataan. Oleh karenanya banyak yang berlomba-lomba untuk mendirikan suatu jasa akomodasi (Artaya, 2016). Hal ini dibuktikan dengan semakin banyaknya hotel berbintang, hotel non-bintang maupun pondok-pondok wisata yang bermunculan di Bali. Namun perkembangan dan pembangunan yang semakin pesat dari waktu ke waktu ternyata tidak hanya melambangkan keberhasilan dari usaha penyedia akomodasi itu sendiri. Pasalnya semakin banyak hotel yang berdiri semakin besar pula dampak yang ditimbulkan (Artaya, 2016).

Salah satu dampak yang cukup terlihat dari pesatnya perkembangan dan pembangunan suatu jasa penyedia akomodasi adalah praktik privatisasi. Privatisasi dapat dimaknai sebagai pemindahan permanen dari aktifitas produksi barang dan jasa yang dilakukan perusahaan negara ke swasta, Dunleavy 1980 (dalam Daulay 2014) atau dapat dikatakan sebagai proses pemindahan kepemilikan dari sektor publik kepada sektor swasta. Mereka beranggapan dengan adanya privatisasi dapat memberikan pelayanan yang lebih guna meningkatkan kenyamanan pengunjung. Sehingga nantinya akan lebih banyak pengunjung yang tertarik dengan fasilitas tersebut dan menggunakan jasa mereka. Padahal dengan adanya privatisasi banyak tempat-tempat yang seharusnya milik umum atau dapat dinikmati bersama, akhirnya hanya bisa dinikmati oleh pengunjung dari penyedia akomodasi tersebut. Akibatnya banyak dari masyarakat lokal maupun wisatawan yang lain tidak dapat melakukan berbagai aktivitas seperti kegiatan keagamaan maupun berekreasi.

Praktik Privatisasi itu sendiri mulai bermunculan di Kawasan Wisata Pantai Sanur, Denpasar. Banyak penyedia akomodasi yang mulai mengkotakkotakkan sempadan pantai di 
area Pantai Sanur sebagai daerah privat miliknnya. Bahkan tidak sedikit juga yang membangun fasilitas tambahan di area sempadan pantai yang diprivatisasi. Sedangkan seharusnya area Sempadan Pantai merupakan kawasan daratan sepanjang tepian laut dengan jarak paling sedikit 100m (seratus meter) dari titik pasang air laut tertinggi ke darat yang mempunyai manfaat penting untuk mempertahankan kelestarian fungsi pantai (Peraturan Kota Denpasar Nomor 27 Tahun 2011 Tentang Rencana Tata Ruang Wilayah Kota Denpasar Tahun 2011-2031). Penggunaan dan pemanfaatan tanah tersebut harus memperhatikan keterbatasan daya dukung serta kepentingan umum (Peraturan Daerah Kabupaten Badung Nomor 26 Tahun 2013 Tentang Rencana Tata Ruang Wilayah Kabupaten Badung Tahun 2013-2033). Salah satu penyedia akomodasi yang diduga melakukan praktik privatisasi sempadan pantai adalah Santrian Resorts and Villas.

Santrian Resort and Villas merupakan penyedia akomodasi yang menaungi dua hotel yang berada di Kawasan Wisata Pantai Sanur. Kedua hotel tersebut ialah, Puri Santrian A Beach Resort and Spa yang berada di Jalan Cemara 35, Kelurahan Sanur dan Griya Santrian A Beach Resort yang berada di Jalan Danau Tamblingan 47, Kelurahan Sanur. Kedua hotel tersebut sama-sama melakukan praktik privatisasi sempadan pantai di Kawasan Pantai Sanur dan juga membangun beberapa fasilitas hotel di area sempadan pantai di Pantai Sanur. Praktik privatisasi sempadan pantai tersebut dapat dilihat dengan adanya papan tanda yang bertuliskan "This area is reserved for hotel guest activity" yang artinya area tersebut sudah dipesan untuk aktivitas pengunjung hotel. Sedangkan salah satu fasilitas hotel yang paling menonjol menyita luas dari sempadan pantai adalah Bar By The Sea yang dimiliki oleh Puri Santrian A Beach Resort and Spa. Bangunan permanen tersebut hanya berjarak kira-kira lima meter dari garis pantai. Jika aktivitas privatisasi dan penggunaan sempadan pantai terus dilakukan, hal tersebut dapat penyebabkan terbatasnya ruang gerak bagi pengguna area umum dan juga memingkatnya dampak negatif akibat bencana serta rusaknya ekosistem. Berdasarkan permasalahan tersebut, menarik diteliti mengenai "Privatisasi Sempadan Pantai oleh Santrian Resorts and
Villas di Pantai Sanur, Denpasar" yang bertujuan untuk mengetahui bentuk privatisasi sempadan pantai oleh Santrian Resort and Spa juga mengetahui kebijakan pemerintah kota Denpasar terhadap privatisasi sempadan pantai tersebut.

\section{TINJAUAN PUSTAKA}

\subsection{Telaah Hasil Penelitian Sebelumnya}

Penelitian mengenai privatisasi

sempadan pantai yang digunakan sebagai acuan dalam penelitian ini yang pertama adalah penelitian dari Sanjiwani (2016) dengan judul "Pengaturan Hukum terhadap Privatisasi Sempadan Pantai oleh Pengusaha Pariwisata di Provinsi Bali". penelitian ini lebih mengacu pada pengaturan hukum mengenai privatisasi sempadan pantai oleh pengusaha pariwisata di provinsi Bali. Sedangkan penelitian kedua dari Sugito, Nanin Trianawati Sugito dan Dede Sugandi (2016) dengan judul "Urgensi Penentuan dan Penegak Hukum Kawasan Sempadan Pantai". Penelitian ini membahas penentuan kawasan sempadan pantai untuk menguatkan kembali fungsi pantai sebagai aset milik umum.

\subsection{Landasan Konsep}

Untuk menganalisis permasalahan yang terdapat dalam penelitian ini, digunakan konsep dan beberapa konsep antara lain teori pengembangan wilayah menurut Hirscham dan Myrdal dalam Nugroho dan Dahuri (2004), konsep privatisasi menurut Clementi (1980) dalam Indra Bastian (2002), konsep sempadan pantai menurut Peraturan Daerah Kabupaten Badung Nomor 26 Tahun 2013 Tentang Rencana Tata Ruang Wilayah Kabupaten Badung Tahun 2013-2033, konsep kebijakan menurut William Dun (1998).

\section{METODE}

Metode penulisan yang digunakan dalam penulisan jurnal ini adalah deskriptif kualitatif dengan teknik penentuan infornan yaitu purposive sampling. Data dalam penelitian ini diperoleh dari sumber primer dan sekunder dengan teknik pengumpulan data yaitu observasi, wawancara mendalam dan studi kepustakan.

Analisis data mula dilakukan saat penyusunan konseptual penelitian, pengupulan data di lapangan. Kemudian dilakukan reduksi data untuk memilah, menajamkan, 
mengarahkan dan membuang data yang tidak diperlukan. Penyajia data dilakukan dalam bentuk teks naratif. Selanjutnya ditarik simpulan yang diverifikasi selama penelitian berlangsung.

\section{HASIL DAN PEMBAHASAN}

\subsection{Wujud dari Privatisasi Sempadan Pantai}

Menurut Mugiyanti (2013) privatisasi merupakan proses pemindahan kepemilikan dari yang awalnya dikelolah oleh negara dan lembagalembaga publik dialihkan menjadi kepemilikan yang sifatnya perseorangan dan individual. Sedangkan Sempadan pantai menurut Peraturan Daerah Kabupaten Badung Nomor 26 Tahun 2013 Tentang Rencana Tata Ruang Wilayah Kabupaten Badung Tahun 2013-2033, adalah kawasan perlindungan perlindungan setempat sepanjang pantai yang mempunyai sifat penting, untuk mempertahankan kelestarian dan kesucian pantai, keselamatan bangunan, dan ketersediaan runag untuk lalu lintas umum. Salah satu ketentuan umum mengenai zonasi kawasan sempadan pantai adalah daratan sepanjang tepian laut dengan jarak palung sedikit $100 \mathrm{~m}$ (seratus meter) dari titik pasang air laut tertinggi ke darat. Dalam penelitian ini Santrian Resorts and Villas jelas melakukan praktik privatisasi yaitu melakukan pemindahan kepemilikan sempadan pantai yang tadinya milik publik menjadi kepemilikan pribadi. Santrian Resorts and Villas juga melanggar aturan tentang pemanfaatan sempadan pantai yang seharusnya area sempadan pantai dengan jarak $100 \mathrm{~m}$ (seratus meter) dari titik pasang air laut tertinggi merupakan area steril yang tidak boleh dimanfaatkan untuk aktivitas maupun peletakan fasilitas hotel. Mengenai wujud dari privatisasi yang dilakukan oleh Santrian Resort and Villas akan dijelaskan lebih lanjut pada uraian sebagai berikut:

Privatisasi sempadan pantai yang dilakukan oleh Puri Santrian A Beach Resort and Spa terlihat sangat jelas. Nampak berbagai fasilitas Puri Santrian A Beach Resort and Spa yang digelar di sepanjang sempadan pantai tersebut, seperti jajaran kursi pantai dan bangunan permanen seperti pos satpam, altar kayu dan juga Bar yang diberi nama "Bar By The Sea". Selain itu ada juga papan tanda yang bertuliskan "The Beach Facilities Are For Puri Santrian Guest Only" yang artinya fasilitas pantai yang ada hanya untuk pengunjung Puri Santrian dan juga ada papan tanda yang bertuliskan "This Area Is Reserved For Hotel Guest
Activity" yang artinya area tersebut sudah dipesan untuk aktivitas pengunjung Puri Santrian A Beach Resort and Spa. Bahkan Puri SantrianA Beach Resort and Spa membangun gubuk sementara di sempadan pantai sebelah utara yang digunakan untuk tempat parkir kapal pribadi milik Puri Santrian. Tidak hanya itu Puri Santrian A Beach Resort and Spa juga memprivat area pantai yang sejajar dengan sempadan pantai tersebut. Yaitu dengan memasang tali-tali pelampung yang terbentang di sepanjang area pantai, selain itu Puri Santrian A Beach Resort and Spa juga meletakkan 2 (dua) pasang kursi pantai terapung di area pantai yang dikhususkan untuk pengunjung hotel.

Sedangkan wujud privatisasi yang dilakukan oleh Griya Santria A Beach Resort juga tidak jauh beda dengan apa yang dilakukan oleh Puri Santrian A Beach Resort and Spa. Terlihat jelas seperti pembuatan lantai kayu permanen dengan ukuran hampir mengambil setengah dari luas area sempadan pantai yang digunakan sebagai alas meletakkan fasilitas restoran seperti meja dan kursi. Ditambah lagi peletakkam kursi pantai didepan fasilitas restoran yang semakin mempersempit luas sempadan pantai yang ada. Juga pemasangan tali-tali pelampung ada di pantai guna untuk memberi tanda wilayah pantai yang menjadi fasilitas Griya Santria A Beach Resort.

Berdasarkan Informasi di atas dapat disimpulkan bahwa Puri Santian A Beach Resort and Spa dan Griya Santrian A Beach Resort benar melakukan praktik privatisasi Sempadan Pantai. Bahkan Puri Santian A Beach Resort and Spa dan Griya Santrian A Beach Resort juga membangun fasilitas hotel di atas area sempadan pantai yang di privat. Selain itu kedua Hotel tersebut juga memprivat area pantai yang sejajar dengan area sempadan pantai yang di privatisasi.

\subsection{Kebijakan Hotel terhadap Area Sempadan Pantai yang di Privat}

\section{a. Kebijakan Hotel Mengenai Aktivitas Wisatawan}

Kebijakan Puri Santrian A Beach Resort and Spa mengenai aktivitas wisatawan selain pengunjung hotel sangat dibatasi. Wisatawan yang bukan pengunjung Puri Santrian A Beach Resort and Spa hanya diizinkan untuk sekedar lewat atau bermain di area yang di privat ketika pengunjung hotel sedikit atau sepi. Mereka sama sekali tidak diizinkan untuk menggunakan fasilitas hotel yang ada. Bahkan jika keadaan Puri Santrian A Beach Resort and 
Spa sedang ramai pengunjung, wisatawan selain pengunjung tidak diperbolehkan berada di area sempadan pantai maupun pantai yang di privatisasi.

Selain itu jika ada wisatawan selain pengunjung Puri Santrian A Beach Resort and Spa yang ini memesan fasilitas yang disediakan seperti kursi pantai maupun ingin menikmati Bar By The Sea juga tidak diperbolehkan. Fasilitas tersebut benar-benar dikhususkan untuk pengunjung yang melakukan pemesanan hotel.

Sama halnya dengan Kebijakan yang dibuat oleh Puri Santrian A Beach Resort and Spa, Griya Santrian A Beach Resort melarang wisatawan selain pengunjung juga menikmati fasilitas yang disediakan Griya Santrian A Beach Resort. Wisatawann yang bukan pengunjung hotel hanya boleh sekedar lewat atau bermain di pantai area tersebut. Namun bedanya Griya Santrian A Beach Resort memperbolehkan jika ada wisatawan yang ingin menyewa fasilitas yang ada. Misalnya ingin menyewa kursi pantai, makan di restoran ataupun berenang di kolam renang yang Griya Santrian A Beach Resort sediakan. Hanya saja hal tersebut diperbolehkan jika kapasitas pengunjung Griya Santrian A Beach Resort sedang sedikit atau tidak ramai. Jika kiranya banyak pengunjung, pihak Griya Santrian A Beach Resort tetap tidak mengizinkan. Sistem tersebut dilakukan demi kenyamanan dan keamanan dari pengunjung Griya Santrian A Beach Resort itu sendiri.

Berdasarkan informasi yang diberikan oleh petugas keamanan Puri Santrian A Beach Resort and Spa dan Griya Santrian A Beach Resort maka dapat di tarik kesimpulan bahwa, kebijakan yang ditetapkan mengenai aktivitas wisatawan terhadap area sempadan pantai yang di privatisasi ialah wisatawan selain pengunjung Puri Santrian A Beach Resort and Spa dan Griya Santrian A Beach Resort tidak boleh sembarangan memasuki ataupun memakai fasilitas yang di sediakan di area Puri Santrian A Beach Resort and Spa dan Griya Santrian A Beach Resort.

\section{b. Kebijakan Hotel Mengenai Aktivitas Masyarakat}

Kebijakan Puri Santrian A Beach Resort and Spa mengenai aktivitas masyarakat dinilai cukup mengekang, karena masyarakat tidak dapat melakukan aktivitas dengan leluasa di area sempadan pantai maupun pantai yang di privatisasi. Memang masyarakat masih bisa melakukan kegiatan rekreasi di area tersebut namun sebagian besar kegiatan seperti Melasti, kegiatan nelayan seperti melaut, memancing ikan dan menyandarkan kapal mereka lebih memilih melakukannya di tempat lain yang bukan merupakan area yang di privatisasi. Hal ini juga disebabkan karena adanya tali-tali pelampung yang sengaja dibuat untuk memberi batas terhadap area yang diprivatisasi. Tapi meskipun begitu Bapak Mangku selaku nelayan di Pantai Sanur mengaku bahwa tidak pernah ada kontra, masalah atau bentrok yang terjadi antara masyarakat dan pihak Puri Santrian A Beach Resort and Spa terkait kebijakan tersebut. Kedua belah pihak sama-sama memaklumi tentang adanya kebijakan yang dibuat oleh Puri Santrian A Beach Resort and Spa.

Sedangkan kebijakan yang dibuat oleh Griya Santrian A Beach Resort sebagian besar juga sama dengan apa yang di buat oleh Puri Santrian A Beach Resort and Spa. Griya Santrian A Beach Resort mengizinkan kegiatan masyarakat yang masih mungkin dilakukan seperti bermain air pantai ataupun memancing di sekitar area yang di privatisasi. Namun untuk kapal nelayan yang ingin sandar memang tidak diperbolehkan untuk sandar di area yang diprivatisasi. Di area pantai diberi tali-tali pelampung yang mana tali tersebut berfungsi sebagai batas juga tanda untuk kapal nelayan agar tidak melewati area yang di privatisasi tersebut.

Bapak Made Roata selaku nelayan anggota Persatuan Jukung Penambang Dewi Satayojana Gandhi Sanur mengaku masih bisa mendapat keuntunganm dengan adanya wisatawan di Griya Santrian A Beach Resort. Memang aktivitasnya sedikit dibatasi di area yang privatisasi, namun para nelayan tesebut diizinkan untuk menawarkan paket yang mereka miliki seperti jalan-jalan menggunakan perahu nelayan, aktivitas memancing, water sports, maupun penyebrangan ke Nusa Penida Ataupun ke Nusa Lembongan. Pihak nelayan dan pihak Griya Santrian A Beach Resort bekerja sama dalam menawarkan paket-paket wisata tersebut.

Berdasarkan informasi yang diberikan oleh petugas keamanan Puri Santrian A Beach Resort and Spa dan Griya Santrian A Beach Resort dan juga para nelayan maka dapat di 
tarik kesimpulan bahwa, kebijakan yang ditetapkan mengenai aktivitas masyarakat terhadap area sempadan pantai yang di privatisasi ialah masyarakat masih bisa menggunakan area sempadan pantai dan pantai yang di privatisasi hanya untuk bermain air ataupun memancing. Kegiatan keagamaan seperti Melasti benar-benar tidak pernah dilakukan disana. Selain itu kapal para nelayan juga dilarang sandar di area sempadan pantai maupun pantai yang diprivatisasi.

\section{c. Kebijakan Hotel Mengenai Aktivitas Usaha Sektor Informal Bidang Pariwisata}

Kebijakan Puri Santrian A Beach Resort and Spa mengenai aktivitas usaha sektor Informal bidang pariwisata menrut Ibu Wayan selaku penjual lumpiah sangat disesalkan, pasalnya beberapa tahun terakhir pedagang benar-benar tidak diperbolehkan berdagang di area yang di privatisasi. Padahal dulu masih diperbolehkan. Jadi kalau ada karyawan Puri Santrian A Beach Resort and Spa atau tamu Puri Santrian A Beach Resort and Spa yang ingin membeli boleh dilayani.

Sama halnya dengan di Puri Santrian A Beach Resort and Spa, di Griya Santrian A Beach Resort pelaku usaha sektor Informal bidang pariwisata tidak diperbolehkan berkeliaran di area yang di privatisasi.Namun di Griya Santrian A Beach Resort terdapat sedikit kelonggaran, kalau ada karyawan Griya Santrian A Beach Resort yang ingin membeli masih diperbolehkan asalkan tahu waktu kapan dia beli. Misalkan di jam istirahat atau sedang tidak bekerja. Namun untuk para tamu Griya Santrian A Beach Resort benar-benar tidak diperbolehkan, karena pihak Griya Santrian A Beach Resort merasa bertanggung jawab selama para tamu tersebut menginap di Griya Santrian A Beach Resort jadi kalau terjadi sesuatu yang tidak diinginkan pasti pihak Griya Santrian A Beach Resort yang kena imbasnya. Oleh karena itu Bapak Suardana selaku petugas keamanan sangat menjaga dengan ketat sebisa mungkin tamu Griya Santrian A Beach Resort tidak membeli barang dagangan dari pelaku usaha sektor Informal bidang pariwisata ini.

Berdasarkan informasi yang diberikan oleh pelaku usaha sektor Informal bidang pariwisata, petugas keamanan Puri Santrian A Beach Resort and Spa dan juga salah satu karyawan Griya Santrian A Beach Resort maka dapat di tarik kesimpulan bahwa, kebijakan yang ditetapkan mengenai aktivitas usaha sektor Informal bidang pariwisata terhadap area sempadan pantai yang di privatisasi dapat dibilang cukup ketat, karena petugas keamanan benar-benar melarang usaha sektor Informal bidang pariwisata tersebut berdagang di area yang di privatisai. Karyawan dari Puri Santrian A Beach Resort and Spa dan Griya Santrian A Beach Resort pun harus sembunyi-sembunyi juka ingin membeli barang dagangan para pelaku usaha sektor Informal bidang pariwisata tersebut.

\subsection{Kebijakan yang dibuat oleh Pemerintah Kota Denpasar}

Kebijakan merupakan aturan tertulis yang merupakan keputusan formal organisasi, yang bersifat mengikat, yang mengatur perilaku dengan tujuan untuk menciptakan tata nilai baru dalam masyarakat. Kebijakan itu sendiri akan manjadi rujukan utama dari para anggota organisasi atau anggota masyarakat dalam berprilaku. Kebijakan biasanya bersifat problem solving dan proaktif. Kebijakan juga lebih bersifat adaptif dan interpretatif (William Dun, 1998).

Kebijakan yang dimaksud dalam penelitian ini adalah kebijakan yang dibuat oleh Pemerintah Kota Denpasar mengenai praktik privatisasi sempadan pantai. Dewasa ini praktik privatisasi sudah menjamur di berbagai daerah. Pemanfaatan sempadan pantai secara berlebihan tentu saja menimbulkan dampak yang serius jika dilakukan secara terusmenerus. Padalah sempadan pantai di tetapkan sebagai salah satu kawasan lindung nasional yang seharusnya dijaga kelestarian dan keberadaannya. Pemerintah memiliki kewenangan penuh terhadap kawasan sempadan pantai yang ada di sepanjang garis pantai Indonesia. Sempadan pantai termasuk dalam kawasan perlindungan setempat (Putri Sanjiwani, 2016).

Pemerintah Kota Denpasar telah mengeluarkan beberapa kebijakan dalam peraturan perundang-undangan untuk perlindungan sempadan pantai, adapun kebijakan tersebut tertuang dalam :

1. Peraturan Daerah Kota Denpasar Nomor 27 Tahun 2011 Tentang Rencana Tata Ruang Wilayah Kota Denpasar Tahun 2011-2031, yang mana dalam peraturan 
tersebut sempadan pantai diatur dalam Pasal 1 Ayat 48 mengenai pengertian sempadan pantai dan Pasal 83 Ayat 3 yang membahas tentang Ketentuan umum peraturan zonasi kawasan sempadan pantai.

2. Peraturan Walikota Denpasar Nomor 6 Tahun 2013 Tentang Peraturan Zonasi Kawasan Strategis Sanur, yang mana dalam peraturan tersebut sempadan pantai diatur dalam Pasal 1 Ayat 27 mengenai pengertian sempadan pantai dan Pasal 12 yang membahas tentang peraturan kegiatan zona sempadan pantai, ketentuan teknis zona sempadan pantai, prasarana dan sarana minimal di zona sempadan pantai dan kententuan lain yang dibutuhkan.

3. Peraturan Walikota Denpasar Nomor 12 Tahun 2014 Tentang Peraturan Zonasi Kecamatan Denpasar Selatan, yang mana dalam peraturan tersebut sempadan pantai diatur dalam Pasal 1 Ayat 30 mengenai pengertian sempadan pantai dan Pasal 14 yang membahas tentang ketentuan zona sempadan pantai untuk kegiatan dan penggunaan lahan, ketentuan intensitas pemanfaatan ruang, ketentuan prasarana dan sarana minimal dan ketentuan lain yang dibutuhkan

4. Peraturan Daerah Kota Denpasar Nomor 5 Tahun 2015 Tentang Bangunan Gedung, yang mana dalam peraturan tersebut sempadan pantai diatur dalam Pasal 25 Ayat 2 mengenai letak garis sempadan bangunan gedung terluar untuk daerah pantai dan Pasal 26 Ayat 9 yang menyebutkan bahwa ketentuan mengenai bangunan di sekitar garis sempadan pantai diatur dalam RTRW (Rencana Tata Ruang Wilayah).

Jika ditelaah dari peraturan perundangundangan diatas memang belun ada peraturan yang mengatur tentang praktik privatisasi sempadan pantai secara langsung. Pemerintah Kota Denpasar hanya menjelaskan tentang zona dan fungsi dari sempadan pantai itu sendiri. Belum ada peraturan untuk menindak lanjuti praktik privatisasi sempadan pantai yang ada. Yang mana praktik privatisasi sempadan pantai tersebut telah menjadi salah satu pelanggaran jika ditinjau dari peraturan yang sudah ada.

\subsection{Konsistensi Pemerintah terhadap kebijakan tersebut}

Konsistensi pemerintah terhadap kebijakan privatisai sempadan pantai masih sangat jauh dari kata sempurna. Hal tersebut dapat dibuktikan dengan kenyataan di lapangan yang mana praktik privatisasi sempadan pantai yang ada di Pantai Sanur tetap berjalan dan aman-aman saja. Peraturan perundangundangan dan kebijakan yang dibuat belum dilaksanakan sebagimana mestinya.

Tidak adanya peraturan yang secara tegas dalam menindak lanjuti siapa saja yang melanggar kebijakan privatisasi sempadan pantai tersebut menjadi salah satu alasan kenapa praktik privatisasi ini masih berlanjut. Selain itu kebijakan mengenai sempadan pantai yang terbilang masih baru, menjadi kendala sendiri bagi pemerintah. Sangat sulit untuk merubah kebiasaan yang sudah dilakukan sejak lama oleh pihak yang melakukan Privatisasi. Yang mana dalam penelitian ini Santrian Resorts adn Villas terlah berdiri kurang lebih 40 tahun yang lalu. Tepatnya Puri Santrian A Beach Resort and Spa saat ini berusia 33 tahun dan Griya Santrian A Beach Resort berusia 46 tahun. Sedangkan kebijakan yang dibuat oleh pemerintah Kota Denpasar baru dikeluarkan pada tahun 2011 yang berarti kebijakan tersebut baru berjalan selama 7 tahun. Tidak hanya itu pemilik hotel (Santrian Resorts and Villas) tersebut juga beranggapan bahwa area sempadan pantai dan juga area pantai tersebut adalah kepemilikan pribadi, mereka dengan bangga menyebutkan bahwa lahan tersebut adalah miliknya.

Kenyamanan dan keamanan pengunjung hotel seringkali dijadikan kedok untuk melakukan praktik privatisasi. Hal yang sama juga dikatakan oleh petugas keamanan di Griya Santrian A Beach Resort, Bapak Suardana mengatakan bahwa area tersebut adalah milik hotel atau sudah menjadi fasilitas hotel, sehingga pihak hotel lah yang memiliki kewenangan atas area sempadan pantai maupun area pantai tersebut. Namun ketika ditanyai lebih lanjut mengenai penggunaan area sempadan pantai dan area pantai tersebut, pihak hotel mengaku hal tersebut sudah mendapatkan izin dari pemerintah setempat.

Selain itu ditemukan fakta lain bahwa, terjadi adanya kesepakatan baru antara pemilik 
hotel dengan pemerintah setempat yang mana hal tersebut akhirnya menjadikan praktik privatisasi yang dilakukan baik oleh Puri Santrian A Beach resort and Spa dan Griya Santrian A Beach Resort dilegalkan. Hal tersebut tidak sengaja diungkapkan oleh petugas keamanan dari Puri Santrian A Beach resort and Spa, bahwa ada praktik pembagian keuntungan antara pihak hotel tersebut dengan pemerintah.

Berdasarkan informasi yang diberikan diatas, tergambarkan bahwa pemerintah masih tidak konsisten terhadap kebijakan yang telah dibuat. Hal tersebut menjadikan pemerintah seolah tutup mata terhapat praktik privatisasi yang dilakukan. Karena pada kenyataannya masih banyak praktik privatisai yang masih saja dilakukan oleh berbagai pihak yang mana dalam penelitian ini dilakukan oleh Santrian Resorts and Villas.

\section{SIMPULAN DAN SARAN 5.2 Simpulan}

Berdasarkan hasil dan pembahasan dapat ditarik kesimpulan bahwa Santrian Resort an Spa, tepatnya Puri Santrian A Beach Resort and Spa dan Griya Santrian A Beach Resort melakukan praktik privatisasi sempadan pantai dan juga pantai yang berhadapan langsung dengan lokasi hotel. Karenanya banyak aktivitas dari wisatawan, masyarakat ataupun pelaku usaha informal bidang pariwisata menjadi tergannggu. Mereka dibatasi dalam melakukan aktivitas seperti rekreasi, melakukan kegiatan keagamaan, mencari ikan maupun berjualan. Merekapun tidak bisa berbuat banyak karena pihak hotel dirasa lebih dominan. Meskipun sudah dibuat peraturan perundang-undangan mengenai sempadan pantai. Tetapi masih belum ada kebijakan yang mengatur secara khusus tentang praktik privatisasi sempadan pantai tersebut. Kebijakan pemerintah yang masih belum tegas dalam menindak lanjuti pelanggaran sempadan pantai itulah yang menjadi salah satu alasan mengapa sampai saat ini praktik privatisasi sempadan pantai tersebut masih marak terjadi.

\subsection{Saran}

Pemanfaatan area sempadan pantai yang telalu berlebihan akan memberikan dampak yang buruk jika dilakukan secara terusmenerus. Oleh karena itu perlu adanya kesadaran baik dari pihak pemerintah, penyedia akomodasi maupun masyarakat lokal tentang penggunaan area sempadan pantai sesuai dengan fungsinya. Kebijakan yang tegas mengenai praktik privatisasi sempadan pantai dari pemerintah pun juga diharapkan dapat segera terwujud agar semua dapat berjalan sebagimana mestinya.

\section{DAFTAR PUSTAKA}

Annonimus. Peraturan Daerah Kabupaten Badung Nomor 26 Tahun 2013 Tentang Rencana Tata Ruang Wilayah Kabupaten Badung Tahun 2013-2033

Annonimus. Peraturan Daerah Kota Denpasar Nomor 5 Tahun 2015 Tentang Bangunan Gedung

Annonimus. Peraturan Kota Denpasar Nomor 27 Tahun 2011 Tentang Rencana Tata Ruang Wilayah Kota Denpasar Tahun 2011-2031

Annonimus. Peraturan Walikota Denpasar Nomor 12 Tahun 2014 Tentang Peraturan Zonasi Kecamatan Denpasar Selatan

Annonimus. Peraturan Walikota Denpasar Nomor 6 Tahun 2013 Tentang Peraturan Zonasi Kawasan Strategis Sanur

Annonimus. Undang-Undang Republik Indonesia Nomor 10 Tahun 2009 Tentang Kepariwisataan

Artaya, Ari. "Kewenangan Pemerintah Kabupaten Badung Dalam Pengendalian Perizinan Pembangunan Sarana Akomodasi Pariwisata." Jurnal Magister Hukum Udayana (Udayana Master Law Journal) 5.3 (2016): 543-558.

Daulay, Nurika Khalila. "Masalah Dan Tantangan Privatisasi Pendidikan Tinggi." Jurnal Tarbiyah 21.2 (2014).

Dunn, William N., Pengantar Analisis Kebijakan Publik, Jogja: Gamapress 1998

Indra Bastian, Privatisasi Di Indonesia; Teori Dan Implementasinya, (Jakarta: Salemba Empat, 2002)

Mugiyanti. "Privatisasi Aset Publik Sebagai Kebijakan Ekonomi Menurut Konsep Al Milkiyah" Al Hikmah Vol.3 (2013)

Nugroho, I Dan Rochimin Danuri. 2004. Pembangunan Wilayah : Perspektif Ekonomi, Sosial Dan Lingkungan. Jakarta : LP3ES

Sanjiwani, Putri Kusuma. "Pengaturan Hukum Terhadap Privatisasi Sempadan Pantai Oleh Pengusaha Pariwisata Di Provinsi Bali."

Sugito, Nanin Trianawati, And Dede Sugandi. "Urgensi Penentuan Dan Penegakan Hukum Kawasan Sempadan Pantai." Jurnal Geografi Gea 8.2 (2016).

Udjianto, Djoko. 2018. Pariwisata Penyumbang Devisa Kedua.

(https://www.tribunnews.com/nasional/2018/05/01/pa riwisata-penyumbang-devisa-kedua) $\quad$ Di akses 30 Januari 2019. 